\section{Pertumbuhan dan Alokasi Biomassa Organ Tanaman Mahoni (Swietenia mahagoni L.) yang Ditanam pada Tanah Bekas Tambang Emas dengan Perlakuan Pupuk Kandang}

\author{
Sri Ambardini \\ Rita Ningsih \\ Yustina Rante Kali
}

\section{BIONATURE}

p-ISSN 1411 - 4720

e-ISSN 2654 - 5160

Abstract. The purpose of this study is to determine the growth and biomass allocation of Mahagony plant organs are planted on ex-gold mining soil with manure treatment. The experimental research with four treatments are control (without manure), manure (cow, goat, chicken) with five replications. The plant growth parameters are observed consist of plant height, stem diameter, leaf number, leaf area, rooth lenght, dry weight, and biomass percentage are located to leaves, stems and plant roots.

The data are tested anova and continue with $t$-test. The result showed that the treatment of manure had efeect on the growth and mahagony planted on ex-golg mining soil. Plant biomass on all manure treatment are largest alloccated to leaves organ then to stems and roots. Based on $t$-test result that the cow manure treatment is better to supporting growth and biomass of mahagony plant than chicken manure, goat manure and control.

Keywords: growth, biomass, mahagony, ex-gold mining soil, manure.

Sri Ambardini Universitas Halu Oleo Indonesia

Rita Ningsih Universitas Halu Oleo Indonesia

Yustina Rante Kali Universitas Halu Oleo Indonesia stabil. Sehingga perlu dilakukan upaya perbaikan kondisi tanah dengan aplikasi teknik amelioran, melalui pemberian pupuk organik dan anorganik, asam humat, serta 
pengapuran untuk mendukung pertumbuhan tanaman, juga dengan melakukan perbaikan sistem drainase untuk mencegah genangan air, dan penyiraman pada tanaman, serta dengan melakukan pemilihan jenis tanaman yang dapat beradaptasi dengan kondisi-kondisi ekstrim tersebut (Mansur, 2010).

Salah satu jenis tanaman yang berpotensi untuk ditanam di daerah ekstrim adalah Mahoni yang memiliki keunggulan, antara lain dapat beradaptasi pada kondisi tanah dan iklim yang beragam sifatnya. Tumbuhan ini dapat berfungsi untuk fitoremediasi lahan kritis, penghijauan dan memperbaiki kondisi kimia tanah atau mengurangi kadar logam dalam tanah (Direktorat Perbenihan Tanaman Hutan, 2001).

Kabupaten Bombana memiliki populasi ternak yang cukup besar diantaranya ayam, kambing dan sapi sehingga produk atau kotorannya dapat digunakan sebagai pupuk kandang. Penggunaan pupuk kandang merupakan salah satu upaya untuk meningkatkan keberhasilan penanaman kembali pada lahan-lahan kritis bekas tambang. Pupuk kandang selain sebagai penyubur tanaman juga mengandung unsur hara yang bermanfaat dalam mengurai pencemaran lingkungan. Oleh karena itu dianggap penting untuk melakukan penelitian mengenai pertumbuhan dan alokasi biomassa organ tanaman mahoni (Swietenia mahagoni L.) yang ditanam pada tanah bekas tambang emas dengan perlakuan pupuk kandang.

\section{Metode Penelitian}

\section{Desain Penelitian}

Uji pertumbuhan tanaman Mahoni (Swietenia mahagoni L.) menggunakan tanah bekas tambang emas dengan perlakuan pupuk kandang dilakukan di dalam rumah kaca jurusan Biologi FMIPA Universitas Halu Oleo. Desain penelitian yang digunakan adalah Rancangan Acak Lengkap (RAL), terdapat 3 unit perlakuan pupuk kandang (sapi, ayam, dan kambing) dan 1 unit kontrol (tanpa pupuk) masing-masing 5 kali ulangan, sehingga seluruhnya terdapat 20 unit percobaan.

\section{Alat}

Alat-alat yang digunakan adalah: Sekop, pacul, saringan tanah, dan karung untuk pengambilan dan tempat sampel tanah bekas tambang yang akan digunakan sebagai media tanam; Keranjang plastik untuk tempat perkecambahan; Polibeg untuk menanam tumbuhan Mahoni; Alat tulis dan Kamera untuk dokumentasi penelitian; Timbangan untuk menimbang sampel tanah bekas tambang dan organ tanaman; Multi tester (pH meter, Higro meter), Lux meter; GPS untuk menentukan titik koordinat tempat pengambilan sampel tanah bekas tambang; Alat tulis dan Komputer sebagai alat pengolah data.

\section{Prosedur Penelitian}

Bahan- bahan yang digunakan dalam penelitian ini adalah: Tanah bekas tambang sebagai sampel yang dianalisis sifat fisika kimia sebelum dijadikan media tumbuh Mahoni; Pupuk dasar (Urea, SP-36, KCl; Pupuk kandang ayam, kambing dan sapi: Air untuk menyiram tanaman selama pertumbuhan. Prosedur kerja dilakukan dengan tahapan sebagai berikut:

\section{Penyiapan Media Tanah}

Tanah yang digunakan yaitu tanah bekas penambangan emas yang diambil dari lokasi pertambangan PT. Panca Logam Makmur Kabupaten Bombana, selanjutnya dibawa ke tempat penelitian di Green House Jurusan Biologi FMIPA UHO. Sampel tanah tersebut dihancurkan lalu dikeringanginkan, Selanjutnya tanah ditimbang untuk dibagi ke dalam polybag yang telah disediakan, berjumlah 20, masing-masing polybag berisi $10 \mathrm{Kg}$ tanah.

\section{Penyiapan Pupuk Kandang}

Pupuk kandang yang digunakan dalam penelitian ini adalah kotoran sapi, kambing, dan ayam yang telah dilakukan pengolahan menjadi pupuk dalam bentuk kering, selanjutnya pupuk 
Pertumbuhan dan Alokasi Biomassa Organ Tanaman Mahoni (Swietenia mahagoni L.) yang Ditanam pada Tanah Bekas Tambang Emas dengan Perlakuan Pupuk Kandang (hlm. 8-14)

dibawa ke tempat penelitian untuk ditimbang masing-masing pupuk kandang berdasarkan polybag yang telah disediakan dengan perbandingan $150 \mathrm{gr} / 10 \mathrm{~kg}$ tanah setara $30 \mathrm{t} / \mathrm{ha}^{-1}$ (Kartasapoetra, 1989) yang selanjutnya dicampur secara merata dengan media tanam (tanah bekas tambang emas).

\section{Membuat Media Tanam}

Pembuatan media tanam untuk perlakuan dan kontrol dilakukan dengan mengisi tanah bekas tambang yang sudah disiapkan sebelumnya ke dalam polibeg. Masing-masing polibeg diisi tanah sebanyak $10 \mathrm{~kg} /$ polibeg ditambah dengan kapur kalsit $10 \mathrm{~g} / 10 \mathrm{~kg}$ tanah dan pupuk kandang 150 gr/pupuk kandang yang dicampur secara merata, untuk media tanam kontrol berisi tanah bekas tambang sebanyak $10 \mathrm{~kg} /$ polibeg yang dicampur dengan kapur kalsit $10 \mathrm{~g} / 10 \mathrm{~kg}$ tanah tanpa penambahan pupuk kandang.

\section{Penanaman Bibit}

Bibit tanaman Mahoni (Swietenia mahagoni L.), yang telah berumur satu bulan ditanam pada polibeg sesuai perlakuan, masing-masing polibeg berisi satu tanaman yang memiliki jumlah daun dan tinggi tanaman relatif homogen. Selanjutnya diletakkan di dalam green house sesuai dengan desain penelitian yang ditentukan secara acak.

\section{Pemeliharaan Tanaman}

Pemeliharaan tanaman di dalam green house terdiri dari:

- Pemberian pupuk dasar menggunakan pupuk urea, SP-36 dan KCL, dengan dosis masingmasing pupuk urea 1,5 gr/10 kg tanah setara dengan $300 \mathrm{~kg} / \mathrm{ha}, \mathrm{SP}-361 \mathrm{gr} / 10 \mathrm{~kg}$ tanah setara dengan $200 \mathrm{~kg} / \mathrm{ha}, \mathrm{KCl} \mathrm{0,5} \mathrm{g} / 10 \mathrm{~kg}$ tanah setara dengan $100 \mathrm{~kg} / \mathrm{ha}$ yang dicampur secara merata, pemberian pupuk secara larikan dengan jarak $5 \mathrm{~cm}$ dari baris tanaman, waktu pemberian pupuk yaitu seminggu setelah tanam.

- Penyiraman, dilakukan setiap hari, menggunakan air dari sumur bor, penyiraman hingga mencapai kelembaban ideal tanah, waktu penyiraman pagi hari jam 08.00 WITA.

\section{Analisis Data}

Pengukuran data pertumbuhan tanaman Mahoni meliputi: Tinggi tanaman $(\mathrm{Cm})$, Diameter batang $(\mathrm{Cm})$, Luas daun $\left(\mathrm{Cm}^{2}\right)$ diukur setiap minggunya dihitung dengan P x L x Konstanta $(0,67)$ (Sitompul dan Guritno, 1995). Jumlah daun (helai), dihitung jumlah daun yang membuka sempurna pada umur 1-12 MST serta berat kering tanaman dan biomassa tanaman yang dialokasi ke organ daun, akar, dan batang. Data yang diperoleh dianalisis menggunakan anava dan dilanjutkan dengan t-test.

\section{Hasil Penelitian}

Hasil pengamatan rerata tinggi tanaman, diameter batang, jumlah daun, luas daun, berat kering total tanaman dan persentase biomassa yang di alokasi ke organ tanaman Mahoni (Swietenia mahagoni L.) yang ditanam pada tanah bekas tambang emas dengan perlakuan pupuk kandang Sapi, Kambing, Ayam dan Kontrol, mulai dari 0 - 12 Minggu Setelah Tanam (MST) disajikan pada tabel dan diagram berikut:

Tabel 1. Rerata Tinggi Tanaman Mahoni (Swietenia mahagoni L.) Pada Umur 0-12 MST (cm)

\begin{tabular}{|c|c|c|c|c|c|c|c|c|}
\hline \multirow{2}{*}{ Perlakuan } & \multicolumn{7}{|c|}{ Tinggi Tanaman (cm) } & \multirow{2}{*}{ Rerata } \\
\cline { 2 - 8 } & $\mathbf{0}$ & $\mathbf{2}$ & $\mathbf{4}$ & $\mathbf{6}$ & $\mathbf{8}$ & $\mathbf{1 0}$ & $\mathbf{1 2}$ & \\
\hline $\mathbf{C}$ & 11,3 & 14,76 & 17,68 & 18,23 & 19,17 & 20,01 & 20,65 & $17,263 \mathbf{a}$ \\
\hline $\mathbf{S}$ & 13,5 & 19,54 & 22,54 & 23,78 & 29,44 & 33,55 & 36,64 & $25,570 \mathbf{b}$ \\
\hline $\mathbf{K}$ & 12,3 & 14,54 & 18,84 & 20,04 & 21,84 & 22,53 & 23,30 & $19,056 \mathbf{b}$ \\
\hline $\mathbf{A}$ & 15,1 & 19,58 & 22,94 & 23,42 & 26,9 & 29,99 & 33,80 & $24,533 \mathbf{b}$ \\
\hline
\end{tabular}

Keterangan: Angka yang diikuti dengan huruf yang sama berbeda tidak nyata pada taraf kepercayaan 95\% C = Tanpa pemberian pupuk kandang (Kontrol); S = Pupuk Kandang Sapi; K = Pupuk Kandang Kambing; A = Pupuk Kandang Ayam 
Tabel 2. Rerata Diameter Tanaman Mahoni (Swietenia mahagoni L.) Pada Umur 1-12 MST (cm)

\begin{tabular}{|c|c|c|c|c|c|c|c|c|}
\hline \multirow{2}{*}{ Perlakuan } & \multicolumn{7}{|c|}{ Diameter Batang (cm) } & \multirow{2}{*}{ Rerata } \\
\cline { 2 - 9 } & $\mathbf{0}$ & $\mathbf{2}$ & $\mathbf{4}$ & $\mathbf{6}$ & $\mathbf{8}$ & $\mathbf{1 0}$ & $\mathbf{1 2}$ & \\
\hline $\mathbf{C}$ & 0,98 & 1,14 & 1,16 & 1,30 & 1,33 & 1,57 & 1,65 & $1,304 \mathbf{a}$ \\
\hline $\mathbf{S}$ & 0,98 & 1,32 & 1,60 & 2,22 & 2,38 & 2,51 & 2,64 & $1,950 \mathbf{b}$ \\
\hline $\mathbf{K}$ & 0,94 & 0,98 & 1,04 & 1,56 & 1,59 & 1,63 & 1,68 & $1,346 \mathbf{b}$ \\
\hline $\mathbf{A}$ & 1,06 & 1,40 & 1,28 & 1,88 & 1,98 & 2,10 & 2,20 & $1,700 \mathbf{b}$ \\
\hline
\end{tabular}

Keterangan: Angka yang diikuti dengan huruf yang sama berbeda tidak nyata pada taraf kepercayaan 95\% C = Tanpa pemberian pupuk kandang (Kontrol); $\mathrm{S}=$ Pupuk Kandang Sapi; K = Pupuk Kandang Kambing; A = Pupuk Kandang Ayam.

Tabel 3. Rerata Jumlah Daun (Helai) Tanaman Mahoni (Swietenia mahagoni L.) Pada Umur 1-12 MST

\begin{tabular}{|c|c|c|c|c|c|c|c|c|}
\hline \multirow{2}{*}{ Perlakuan } & \multicolumn{7}{|c|}{ Jumlah Daun (Helai) } & \multirow{2}{*}{ Rerata } \\
\cline { 2 - 9 } & $\mathbf{0}$ & $\mathbf{2}$ & $\mathbf{4}$ & $\mathbf{6}$ & $\mathbf{8}$ & $\mathbf{1 0}$ & $\mathbf{1 2}$ & $9,88 \mathbf{a}$ \\
\hline $\mathbf{C}$ & 3,60 & 7,40 & 8,40 & 10,00 & 11,20 & 13,10 & 15,50 & $23,85 \mathbf{b}$ \\
\hline S & 5,20 & 12,2 & 13,00 & 27,60 & 25,50 & 38,50 & 45,00 & $14,34 \mathbf{a}$ \\
\hline K & 5,20 & 9,20 & 10,20 & 14,60 & 18,20 & 20,40 & 22,60 & $21,15 \mathbf{b}$ \\
\hline
\end{tabular}

Keterangan: Angka yang diikuti dengan huruf yang sama berbeda tidak nyata pada taraf kepercayaan 95\% C = Tanpa pemberian pupuk kandang (Kontrol); $\mathrm{S}=$ Pupuk Kandang Sapi; K = Pupuk Kandang Kambing; A = Pupuk Kandang Ayam.

Tabel 4. Rerata Luas Daun Tanaman Mahoni (Swietenia mahagoni L.) Umur 1-12 MST

\begin{tabular}{|c|c|c|c|c|c|c|c|c|}
\hline \multirow{2}{*}{ Perlakuan } & \multicolumn{7}{|c|}{ Luas Daun (cm) } & \multirow{2}{*}{ Rerata } \\
\hline & 0 & 2 & 4 & 6 & 8 & 10 & 12 & \\
\hline C & 9,20 & 11,10 & 11,99 & 13,25 & 15,66 & 20,85 & 20,87 & $14,70 \mathbf{a}$ \\
\hline$S$ & 10,33 & 12,20 & 15,10 & 20,50 & 24,11 & 30,45 & 49,25 & $23,13 \mathbf{b}$ \\
\hline $\mathbf{K}$ & 9,50 & 10,90 & 13,03 & 17,88 & 20,13 & 26,99 & 30,62 & $18,43 \mathbf{a}$ \\
\hline $\mathbf{A}$ & 10,10 & 11,84 & 14,27 & 19,62 & 22,50 & 27,07 & 33,60 & $20,85 b$ \\
\hline
\end{tabular}

Keterangan: Angka yang diikuti dengan huruf yang sama pada baris berbeda tidak nyata pada taraf kepercayaan 95\% C = Tanpa pemberian pupuk kandang (Kontrol); $\mathrm{S}=$ Pupuk Kandang Sapi; K = Pupuk Kandang Kambing; A = Pupuk Kandang Ayam.

Tabel 5. Rerata Berat Kering Total Tanaman Mahoni (Swietenia mahagoni L.) umur 12 MST

\begin{tabular}{|c|c|c|c|c|c|c|}
\hline \multirow{2}{*}{ Perlakuan } & \multicolumn{5}{|c|}{ Berat Kering Total Tanaman (g) } & \multirow{2}{*}{ Rerata } \\
\cline { 2 - 7 } & $\mathbf{1}$ & $\mathbf{2}$ & $\mathbf{3}$ & $\mathbf{4}$ & $\mathbf{5}$ & $3.30 \mathbf{a}$ \\
\hline $\mathbf{C}$ & 4,90 & 3,40 & 0,00 & 1,70 & 3,20 & $15.02 \mathbf{b}$ \\
\hline $\mathbf{S}$ & 8,30 & 20,40 & 12,90 & 13,60 & 19,90 & $4.76 \mathbf{a}$ \\
\hline K & 8,50 & 0,50 & 3,20 & 0,90 & 10,70 & $14.78 \mathbf{b}$ \\
\hline A & 8,50 & 25,90 & 5,60 & 11,20 & 22,70 & . \\
\hline
\end{tabular}

Keterangan: Angka yang diikuti dengan huruf yang sama berbeda tidak nyata pada taraf kepercayaan 95\% C = Tanpa pemberian pupuk kandang (Kontrol); S = Pupuk Kandang Sapi; K = Pupuk Kandang Kambing; A = Pupuk Kandang Ayam. 
Pertumbuhan dan Alokasi Biomassa Organ Tanaman Mahoni (Swietenia mahagoni L.) yang Ditanam pada Tanah Bekas Tambang Emas dengan Perlakuan Pupuk Kandang (hlm. 8-14)

Nilai persentase biomassa tanaman yang dialokasikan ke daun, batang, dan akar Tanaman Mahoni (Swietenia mahagoni L.) pada perlakuan pupuk kandang dan kontrol disajikan pada Gambar 6.
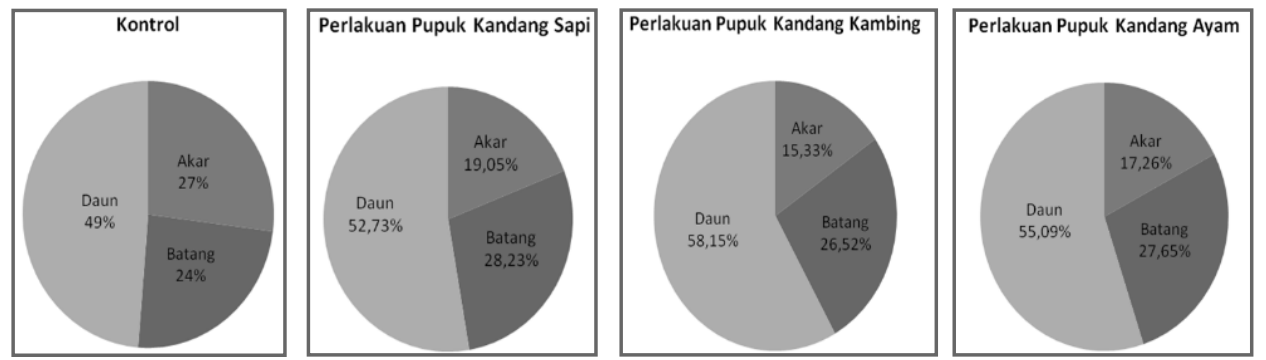

Gambar 6. Persentase Biomassa Tanaman yang Dialokasikan Ke Daun, Batang, dan Akar pada Kontrol dan dengan Perlakuan Pupuk Kandang pada Umur 12 MST

\section{Pembahasan}

Tanaman Mahoni dapat tumbuh pada tanah bekas tambang emas Bombana meskipun dengan pertumbuhan yang lebih lambat dibandingkan dengan pertumbuhan tanaman Mahoni yang diberi perlakuan pupuk kandang. Berdasarkan analisis statistik menunjukkan bahwa perlakuan pupuk kandang berbeda nyata dengan kontrol pada semua parameter pertumbuhan yang diamati $(\mathrm{P}<0,05)$. Sedangkan untuk pupuk kandang sendiri mempunyai pengaruh yang berbeda dalam merangsang pertumbuhan Mahoni. Pada parameter tinggi tanaman dan diameter batang tanaman terlihat bahwa ketiga pupuk kandang (sapi, kambing dan ayam) tidak menunjukkan perbedaan nyata secara statistik, meskipun demikian dari data kuantitatif perlakuan pupuk kandang sapi menunjukkan rerata pertumbuhan tertinggi, yaitu $25,57 \mathrm{~cm}$ dan rerata pertumbuhan diameter terbesar, yaitu $1,95 \mathrm{~cm}$.

Perlakuan pupuk kandang sapi juga menunujukkan rerata pertumbuhan jumlah daun terbanyak $\left(23,85\right.$ helai) dan luas daun terlebar $\left(23,13 \mathrm{~cm}^{2}\right)$, namun perlakuan pupuk kandang sapi ini tidak berbeda nyata dengan perlakuan pupuk kandang ayam, hanya berbeda nyata dengan perlakuan pupuk kandang kambing dan kontrol. Tingginya rerata pertumbuhan tanaman Mahoni yang diberi pupuk kandang sapi disebabkan karena kandungan unsur hara makro Nitrogen (N), Posfor (P), dan Kalium (K) yang terkandung di dalam pupuk kandang sapi yang diberikan lebih tinggi daripada kandungan unsur hara NPK pada pupuk kandang kambing dan pupuk kandang ayam, hal ini dibuktikan dengan hasil analisis unsur hara makro NPK yang terkandung di dalam ketiga macam pupuk kandang yang dilakukan pada awal penelitian, yaitu: untuk Pupuk kandang sapi N 0,58\%, P 12,67\%, K 0,53; pupuk kandang kambing yaitu N 0,41\%, P 11,24\%, K 0,31\% dan pupuk kandang ayam yaitu N 0,37\%, P 11,35\% dan K 0,36\%. Disamping kelebihan kandungan unsu hara NPK, pupuk kandang sapi juga memiliki kelebihan sebagai pupuk dingin yang diuraikan secara perlahan oleh mikroorganisme sehingga tidak menimbulkan panas, berbeda dengan pupuk kandang kambing dan pupuk kandang ayam yang tergolong pupuk panas karena diuraikan mikroorganisme secara cepat sehingga menimbulkan panas (Tan, 1993).

Perlakuan pupuk kandang pada tanah bekas tambang emas sangat membantu penyediaan unsur hara esensial makro dan mikro yang berguna bagi pertumbuhan tanaman, dan komposisi yang terdapat pada pupuk kandang sapi yang paling sesuai untuk mendukung pertumbuhan tanaman mahoni. Perlakuan pupuk kandang juga dapat meningkatkan berat kering total tanaman Mahoni (Swietenia mahagoni L.) dibandingkan berat kering daun tanpa pupuk kandang. Berat kering tanaman merupakan hasil penimbunan dari hasil asimilasi bersih selama pertumbuhan tanaman (Gardner et al., 1991). Prawiranata dkk., (1989) menyatakan bahwa berat kering mencerminkan penyerapan nutrisi tanaman. Ukuran berat kering tergantung juga pada laju fotosintesis. Setyati (1991) menyatakan bahwa peningkatan hasil fotosintesis merupakan penampilan ukuran dari berat kering yang mencerminkan bertambahnya protoplasma karena baik ukuran sel maupun jumlah sel akan bertambah. 
Alokasi biomassa tanaman Mahoni menunjukkan tren yang sama baik yang diberi perlakuan pupuk pandang maupun pada kontrol, yaitu biomassa terbanyak dialokasikan ke daun kemudian batang dan terakhir pada akar, hal ini sebagai konsekuensi logis bagi pertumbuhan tanaman mahoni yang masih berumur 12 MST dimana pada fase ini merupakan fase pertumbuhan muda yang masih perlu banyak membentuk daun sebagai organ fotosintesis utama, hasil ini juga didukung dengan oleh Schuzle dan Cadwell (1995) yang menyatakan ketersediaan hara terutama unsur $\mathrm{N}$ akan meningkatkan alokasi biomassa tanaman terutama pada daun dan batang.

Biomassa tanaman meliputi semua bahan tanaman yang dihasilkan dari proses fotosintesis yang menggunakan unsur hara dan air yang diolah melalui proses biosintesis (Sitompul dan Guritno, 1995). Hal ini sejalan dengan hasil biomassa tanaman mahoni (Swietenia mahagoni L.) yang diteliti, menunjukkan biomassa tanaman terbesar diperoleh pada perlakuan pupuk kandang sapi, dengan alokasi biomassa tertinggi pada daun selanjutnya batang dan akar. Sedangkan biomassa terendah pada perlakuan kontrol tanpa adanya pupuk kandang.

\section{Kesimpulan}

Berdasarkan hasil penelitian maka dapat disimpulkan bahwa pertumbuhan tanaman mahoni (Swietenia mahagoni L.) yang ditanam pada tanah bekas tambang emas berbeda nyata antara yang diberi perlakuan pupuk kandang dengan yang tanpa pupuk kandang (kontrol). Perlakuan pupuk kandang sapi secara kuantitatif menunjukkan pertumbuhan yang lebih baik dibanding perlakuan pupuk kandang ayam dan kambing, dan secara statistik berbeda nyata dengan pupuk kandang kambing namun tidak berbeda nyata dengan pupuk kandang ayam. Biomassa tanaman mahoni (Swietenia mahagoni L.) pada semua perlakuan pupuk kandang dan kontrol paling banyak dialokasikan pada organ daun kemudian batang dan akar.

\section{Referensi}

Ahyani, M. (2011). Pengaruh Kegiatan Penambangan Emas Terhadap Kondisi Kerusakan Tanah Pada Wilayah Pertambangan Rakyat di Bombana Sulawesi Tenggara. Tesis. Program Magister Ilmu Lingkungan, Program Pasca Sarjana Universitas Diponegoro, Semarang.

Darwis, A., Zaeni \& Sarlan. (2010). Pengaruh Bokasi Terhadap Pertumbuhan Tanaman Pada Tanah Terkontaminasi Nikel (Suatu Studi Remediasi). Skripsi FMIPA Universitas Halu Oleo, Kendari.

Gardner, F.P., Pearce R.B., \& Mithchell R.L.. (1991). Fisiologi Tanaman Budidaya. Universitas Indonesia (UI-Press), Jakarta.

Lingga, P., \& Marsono. (2001). Petunjuk Penggunaan Pupuk. Penebar Swadaya. Jakarta

Mangel, K., \& Kirkby, E.A. (1987). Principle of Plant Nutrition. Edition. International Potash Institute. Berm

Mansur. (2010). Teknik Silvikultur Untuk Reklamasi Lahan Bekas Tambang. Seameo Biotrop. Bogor, Indonesia.

Prawiranata, W. S., S. Hairan, \& Tjondronegoro, P. (1989). Dasar-Dasar Fisiologi.

Sarief, S. 1985. Kesuburan dan Pemupukan Tanah Pertanian. Pustaka Buana. Bandung.

Setyati, 1991. Pengantar Agronomi. Gramedia Pustaka Utama. Jakarta.

Setyati, 1991. Tanaman Jilid II. Gramedia Pustaka Utama. Jakarta. 
Pertumbuhan dan Alokasi Biomassa Organ Tanaman Mahoni (Swietenia mahagoni L.) yang Ditanam pada Tanah Bekas Tambang Emas dengan Perlakuan Pupuk Kandang

e-ISSN 2654-5160 p-ISSN 1411-4720 (hlm. 8-14)

Sitompul, S.M., \& Guritno, B. (1995). Analisis Pertumbuhan Tanaman. Gadjah Mada University Press. Yogyakarta.

Sutedjo, M. M. (2002). Analisis Tanaman, Kanisius, Jakarta.

Sutedjo, M. M \& A. G. Kartasapoetra, (1994). Pupuk dan Cara Pemupukan, Bina Aksara, Jakarta.

\begin{tabular}{|l|l|}
\hline Sri Ambardini & $\begin{array}{l}\text { Jurusan Biologi FMIPA Universitas Halu Oleo } \\
\text { E-mail: ambardiniwin@gmail.com }\end{array}$ \\
\hline Rita Ningsih & $\begin{array}{l}\text { Jurusan Biologi FMIPA Universitas Halu Oleo } \\
\text { E-mail: ambardiniwin@gmail.com }\end{array}$ \\
\hline Yustina Rante Kali & $\begin{array}{l}\text { Jurusan Biologi FMIPA Universitas Halu Oleo } \\
\text { E-mail: ambardiniwin@gmail.com }\end{array}$ \\
\hline
\end{tabular}

